\title{
Economic impact of clinical decision support interventions based on electronic health records
}

\author{
Daniel Lewkowicz $^{1 *}$, Attila Wohlbrandt ${ }^{1}$ and Erwin Boettinger ${ }^{1,2}$
}

\begin{abstract}
Background: Unnecessary healthcare utilization, non-adherence to current clinical guidelines, or insufficient personalized care are perpetual challenges and remain potential major cost-drivers for healthcare systems around the world. Implementing decision support systems into clinical care is promised to improve quality of care and thereby yield substantial effects on reducing healthcare expenditure. In this article, we evaluate the economic impact of clinical decision support (CDS) interventions based on electronic health records (EHR).
\end{abstract}

Methods: We searched for studies published after 2014 using MEDLINE, CENTRAL, WEB OF SCIENCE, EBSCO, and TUFTS CEA registry databases that encompass an economic evaluation or consider cost outcome measures of EHR based CDS interventions. Thereupon, we identified best practice application areas and categorized the investigated interventions according to an existing taxonomy of front-end CDS tools.

Results and discussion: Twenty-seven studies are investigated in this review. Of those, twenty-two studies indicate a reduction of healthcare expenditure after implementing an EHR based CDS system, especially towards prevalent application areas, such as unnecessary laboratory testing, duplicate order entry, efficient transfusion practice, or reduction of antibiotic prescriptions. On the contrary, order facilitators and undiscovered malfunctions revealed to be threats and could lead to new cost drivers in healthcare. While high upfront and maintenance costs of CDS systems are a worldwide implementation barrier, most studies do not consider implementation cost. Finally, four included economic evaluation studies report mixed monetary outcome results and thus highlight the importance of further high-quality economic evaluations for these CDS systems.

Conclusion: Current research studies lack consideration of comparative cost-outcome metrics as well as detailed cost components in their analyses. Nonetheless, the positive economic impact of EHR based CDS interventions is highly promising, especially with regard to reducing waste in healthcare.

Keywords: Economic evaluation, Electronic health record, Clinical decision support, Behavioral economics

\footnotetext{
* Correspondence: daniel.lewkowicz@hpi.de

'Digital Health Center, Hasso Plattner Institute, University of Potsdam,

Prof.-Dr.-Helmert-Str. 2-3, 14482 Potsdam, Germany

Full list of author information is available at the end of the article
}

(C) The Author(s). 2020 Open Access This article is licensed under a Creative Commons Attribution 4.0 International License, which permits use, sharing, adaptation, distribution and reproduction in any medium or format, as long as you give appropriate credit to the original author(s) and the source, provide a link to the Creative Commons licence, and indicate if changes were made. The images or other third party material in this article are included in the article's Creative Commons licence, unless indicated otherwise in a credit line to the material. If material is not included in the article's Creative Commons licence and your intended use is not permitted by statutory regulation or exceeds the permitted use, you will need to obtain permission directly from the copyright holder. To view a copy of this licence, visit http://creativecommons.org/licenses/by/4.0/ The Creative Commons Public Domain Dedication waiver (http://creativecommons.org/publicdomain/zero/1.0/) applies to the data made available in this article, unless otherwise stated in a credit line to the data. 


\section{Contributions to the literature}

- A recent economic analysis of implemented clinical decision support (CDS) interventions based on electronic health records (EHR) is presented based on previous reviews.

- Different EHR based CDS tools are prioritized and weighted regarding their economic benefit. This study provides policymakers, clinic managers, and other healthcare providers, who intend to implement similar health information technology, with a better understanding of valuable interventions and their application areas.

- The small number of model-based economic evaluations and the studies' heterogeneity are regarded as indicators that information about costs and benefits is not extensively reported in the scientific literature.

\section{Background}

As stated in the 2017 OECD health report, the annual average growth rate in per capita health expenditure continued to increase by $1.7 \%$ in Germany and $2.1 \%$ in the US in real terms since 2009 [1]. Healthcare expenditure per capita was estimated to be $\$ 5551$ in Germany but was yet outspent by the United States, with almost $80 \%$ higher spending per capita [1]. The latest OECD Health Statistics 2019 report reconfirms these numbers on rising healthcare expenditure, and yet reveals an increase of spending per capita to $\$ 5986$ in Germany and $\$ 10,586$ in the US, which is equal to $11.2 \%$ and $16.9 \%$ of total GDP, respectively [2].

Unnecessary healthcare utilization, non-adherence to current clinical guidelines, or insufficient personalized care are perpetual challenges and remain potential major cost-drivers for healthcare systems around the world [3, 4]. For instance, a recent review estimated the annual cost of waste in the US healthcare system between $\$ 760$ billion and $\$ 935$ billion, which accounts for $25 \%$ of total healthcare spending [3]. Furthermore, Shrank et al. [3] approximated that $\$ 191$ billion to $\$ 282$ billion could be saved annually with the use of systematic interventions that address the reduction of waste in healthcare.

The benefits of electronic health records (EHR) culminate in the integration of computerized provider order entry (CPOE) systems and real-time, point of care clinical decision support (CDS) interventions. Introducing decision support systems into clinical care is promised to improve quality of care and thereby yield substantial effects on reducing healthcare expenditure [5]. In addition, the growing field of behavioral economics explores how different interventions, such as nudges or best-practicealerts (BPA), influence and improve clinical decision making through various applicable concepts $[6,7]$.
The goal of this study is to explore the economic impact of EHR based CDS interventions and to identify a coherent best practice approach for these clinical interventions from a cost outcome perspective. Finally, we seek to examine cost-saving or cost-effective application areas for different medical risk factors.

\section{Methods}

\section{Search strategy}

We conducted a systematic literature review to identify the current research progress regarding the economic impact and benefits of clinical decision support interventions based on EHRs. Following the preferred reporting items for systematic reviews and meta-analyses (PRISMA) statement [8], we searched English-language literature indexed in the following databases: (1) PubMed, (2) Cochrane Central Register of Controlled Trials (CENT RAL) in the Cochrane Library, (3) Web of Science, (4) EBSCO Business Source Complete, and (5) CEA Registry Tufts Medical Center Library. Additionally, we screened the reference lists of all included studies for eligibility. The literature screening process was completed on January 10th, 2020.

To achieve high sensitivity and precision, we developed each search query based on three main pillars: (a) economic outcome, (b) electronic health record, and (c) clinical decision support. These main terms are then further extended with specific terminology and synonyms using Boolean operators to complete the search strategy. We used MeSH terms for the search in PubMed (1) and comparable search terms in databases (2)-(4). For the basic CEA registry search (5), only basic key search terms were used. A detailed summary of the developed search queries is listed in an additional file (see Additional file 1).

\section{Inclusion criteria}

We included all trials in which a monetary economic outcome of an implemented EHR based CDS system is reported. Thus, we considered all analyses of inpatient or ambulatory financial data measures as well as trialbased modelling predictions. We also included all kinds of model perspectives, i.e., societal, health insurance, health systems, or user-centered perspective, to identify the complete economic dimension of an EHR based CDS intervention. We summarized the detailed inclusion and exclusion criteria of this systematic economic review in Table 1.

A pre-search showed that prior systematic reviews adequately elaborate the timeframe until 2014, and we, therefore, include only studies published from 2014 to 2020. During our search process, we found that the number of studies meeting the inclusion criteria increased tremendously in the past years, partially overlapping the present research question [9-11]. The most 
Table 1 Inclusion and exclusion criteria

\begin{tabular}{|c|c|c|}
\hline & Inclusion criteria & Exclusion criteria \\
\hline $\begin{array}{l}\text { Type of decision } \\
\text { support intervention }\end{array}$ & $\begin{array}{l}\text { Any real-time and near real-time (point-of-care) } \\
\text { computerized clinical decision intervention } \\
\text { based on an EHR }\end{array}$ & $\begin{array}{l}\text { - Decision support via e-mail, telephone contact, expert training } \\
\text { or workshop, non-computerized education materials, or other } \\
\text { behavioral economics interventions, such as accountable } \\
\text { justification, i.e., free text entry, or peer comparison via e-mail } \\
\text { - Retrospectively generated EHR based CDS alerts, e.g., for } \\
\text { retrospective comparison or estimation } \\
\text { - Basic CPOE without any decision stewardship } \\
\text { - Cost or price display in order to facilitate cost-consciousness } \\
\text { - BPA for EHR based patient recruitment for clinical trials } \\
\text { - CDS for transitional care to improve post-discharge utilization } \\
\text { and discharge management, i.e., process management } \\
\text { - CDS usage for resource management, e.g., nurse staffing } \\
\text { - EHR based CDS usage support through pay4performance } \\
\text { incentives }\end{array}$ \\
\hline Economic outcome & $\begin{array}{l}\text { Monetary outcome data reported through } \\
\text { quantitative cost-calculations or estimated } \\
\text { through clinical trial-based modelling } \\
\text { techniques }\end{array}$ & $\begin{array}{l}\text { Other economic outcome measures, e.g., length of stay, } \\
\text { amount of emergency department visits or primary care } \\
\text { consultations }\end{array}$ \\
\hline
\end{tabular}

recent review by Jacob et al. [9] examined the cost and economic benefits of CDS systems restricted to cardiovascular disease prevention. However, the authors were unable to conclude whether these interventions were cost-beneficial or cost-effective. Moja et al. [10] reviewed randomized controlled trials (RCTs) that examined the effectiveness of EHR based CDS systems with regard to mortality, morbidity, and economic outcomes. The authors report that EHR based CDS interventions resulted in only small differences in cost and health service utilization.

\section{Front-end CDS interventions}

Wright et al. [12] developed a taxonomy of front-end CDS interventions available to EHR users, which we adopt into this study. In contrast to back-end system capabilities, the authors defined front-end CDS tools as "the intervention types available to end-users created using specific clinical knowledge bases and application logic [12]." Their taxonomy consists of 53 designed CDS front-end tools, i.e., interventions, that were further categorized into six categories [12]:

1. Medication dosing support

2. Order facilitators

3. Point-of-care alert or reminders

4. Relevant information display

5. Expert systems

6. Workflow support

We utilize this taxonomy to analyze application areas of significant cost-savings. For this, we prioritize and weight different EHR based CDS tools based upon their economic benefit. This approach can give policymakers, clinic managers, and other healthcare providers a better understanding of valuable EHR based CDS interventions and their application areas to implement similar health information technology.

\section{Results}

We screened in total 1309 publications, of which 27 studies meet our inclusion criteria for this economic review [5, 13-38]. The process of our literature search and the reasons for excluding several studies is provided within the PRISMA flow-diagram in Fig. 1. An overview of the characteristics of the included studies is listed in Table 2.

Generally, 22 studies (81\%) [5, 13-16, 18, 20-25, $28-32,34-38]$ out of the included 27 studies report cost savings after implementing an EHR based CDS intervention. Four studies (15\%) [17, 26, 27, 33] report a rise in cost expenditure. The remaining study (4\%) [19] did not detect significant differences in cost outcomes. In the majority of included studies the main cost outcome measures were related to laboratory test cost [15-17, 20, $21,25,28,29,31,32,38]$.

\section{Exploration of different front-end CDS intervention categories}

According to the taxonomy by Wright et al. [12], we identified $10(37 \%)$ studies $[5,13,15,20,22,23,26$ 36-38] which explored EHR based CDS interventions based on point-of-care alerts or reminders (category 3). Three interventions (11\%) [17, 27, 34] were order facilitators (category 2). Medication dosing support, relevant information display, and expert systems (categories 1, 4, and 5) were each reported only once from an economic perspective (11\%) $[18,19,24]$. In eight studies (30\%) [14, $16,25,28,30,31,33,35]$, interventions from two different categories were explored in combination. Moreover, we found three studies (11\%) [21, 29,32] in which the option to place a certain order or test, e.g., a laboratory test, was 


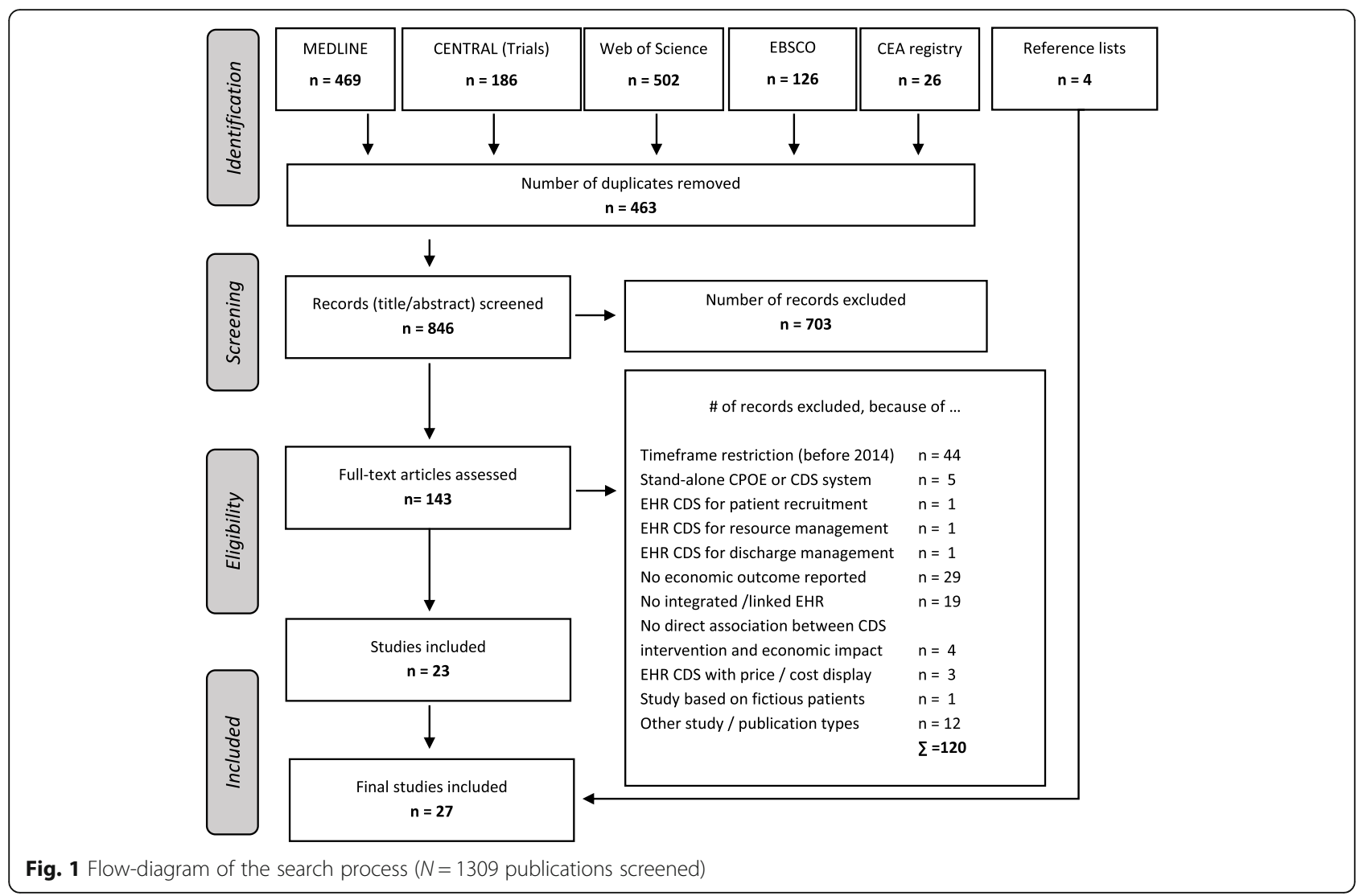

removed from the EHR CPOE system or the clinician's laboratory ordering preference list. These restrictive frond-end CDS intervention types were not yet mentioned in the predefined categories by Wright et al. [12]. Thus, we extend their taxonomy by a new category:

\section{Restriction of choice [39]}

The removal of an order option ultimately resulted in fewer laboratory tests and reduced healthcare expenditure in all studies [14, 28, 31]. Finally, we identified two different types of implemented hard-stops [40]: an interruptive alert [30] and a restrictive hard-stop [14]. An interruptive alert requires a clicking response from the physician before being able to move forward. A restrictive hard-stop prevents the physician from ordering a test, e.g., by directing them to call the laboratory director. We grouped studies regarding the interruptive alert intervention to category 3 and the restrictive hardstop intervention to category 7.

\section{Economic impact for prevalent application areas}

In Table 3, we summarized our findings and created an overview of application areas and cost outcome measures in relation to the applied CDS intervention types.
The included studies show a high heterogeneity with regard to different types of reported cost outcomes and different intervention durations. Due to this complexity, it was not possible to conduct a subgroup analysis regarding the economic impact of each CDS-front end category. A detailed evidence synthesis of all included 27 studies and a brief description of their intervention types, their application area, and the resulting economic impact are provided in an additional file (see Additional file 2).

\section{Application areas for cost-savings}

We identified four primary application areas based on their investigated prevalence that resulted in costsavings after EHR based CDS implementation. Firstly, two studies report on reducing unnecessary Vitamin D routine testing, which led to a decrease in laboratory test cost of $\$ 300,000$ [15] and \$1.4 mill. [28] per year.

Secondly, two studies addressed the economic outcome of reducing waste in transfusion practice and red blood cell usage [36, 37]. The acquisition product cost of red cell units was decreased with the help of EHR based CDS and resulted in cost savings of $\$ 4,821,000$ after 3 years [36] and about $\$ 62,715$ within 1 year [37] after implementation, respectively. 
Table 2 Characteristics of included studies $(n=27)$

\begin{tabular}{|c|c|}
\hline Category & Number of studies (\% of total, rounded) \\
\hline \multicolumn{2}{|l|}{ Country } \\
\hline United States & $24(89 \%)[5,13-18,20,22,23,25-38]$ \\
\hline Canada & $3(11 \%)[19,21,24]$ \\
\hline \multicolumn{2}{|l|}{ Year published } \\
\hline 2019 & $6(22 \%)[13-18]$ \\
\hline 2018 & $6(22 \%)[5,19-23]$ \\
\hline 2017 & $5(19 \%)[24-28]$ \\
\hline 2016 & $2(7 \%)[29,30]$ \\
\hline 2015 & $3(11 \%)[31,33,34]$ \\
\hline 2014 & $5(19 \%)[32,35-38]$ \\
\hline \multicolumn{2}{|l|}{ Study design } \\
\hline Cluster randomized trial & $4(15 \%)[5,19,26,33]$ \\
\hline Cross-sectional & $1(4 \%)[28]$ \\
\hline Retrospective & $9(33 \%)[15,17,18,20,21,27,32,36,38]$ \\
\hline Quasi-experimental & $5(19 \%)[14,16,22,24,35]$ \\
\hline Comparative & $1(4 \%)[31]$ \\
\hline Observational & $1(4 \%)[23]$ \\
\hline Pre-post-intervention & $6(22 \%)[13,25,29,30,34,37]$ \\
\hline \multicolumn{2}{|l|}{ Setting } \\
\hline Inpatient & $\begin{array}{l}14(51 \%)[14,16,17,20,22-25,27,31,32,34, \\
36,38]\end{array}$ \\
\hline Outpatient & $8(30 \%)[5,13,15,19,26,30,33,34]$ \\
\hline $\begin{array}{l}\text { Inpatient \& } \\
\text { outpatient }\end{array}$ & $4(15 \%)[21,28,29,37]$ \\
\hline $\begin{array}{l}\text { Emergency } \\
\text { department }\end{array}$ & $1(4 \%)[18]$ \\
\hline \multicolumn{2}{|c|}{ Type of economic evaluation } \\
\hline $\begin{array}{l}\text { Basic cost } \\
\text { calculation }\end{array}$ & $23(85 \%)[13-25,27-32,34,36-38]$ \\
\hline Model approach & $4(15 \%)[5,26,33,35]$ \\
\hline
\end{tabular}

Thirdly, two cost-effectiveness analyses modeled the cost outcome of reducing antibiotic prescriptions for acute respiratory infection and acute bronchitis [5, 33]. Gong et al. [5] include a full accounting of costs into their Markov model, and explore that the implemented CDS intervention, called "suggested alternatives", yielded more quality adjusted life years (QALYs) at a lower cost of $\$ 500,000$ per 100,000 individuals over 30 years of implementation. Michaelidis et al. [33] report only a small increase in costs compared to a printed decision support system, i.e., posters. However, the latter mainly results from a cost difference between the direct costs of poster printing and computer programming.

Lastly, five studies $[20,29,31,32,38]$ report on the potential to reduce duplicate orders, e.g., duplicate laboratory tests, using hard-stops [32] or order frequency rules [20]. Order frequency rules prevent ordering the same test within a specified timeframe. Reducing duplicate laboratory tests resulted in savings of $\$ 3395$ after 3 months for a small patient size cohort [38], and up to $\$ 315,565$ within 24 month for a large patient size cohort [29].

\section{Application areas resulting in cost increase}

We also identified risk areas, which possibly lead to a further increase in healthcare expenditure. One study found that specialized HIV laboratory testing cost increased by $\$ 14,000-\$ 96,000$ within 6 months after implementing a CPOE system with default settings [17]. Another study reports that an unplanned change of a pre-selected default order for 'complete blood count' to 'complete blood count with differential' led to an average cost increase of $\$ 293.11$ per day [27]. Finally, the implementation of order sets as decision facilitators possibly entails adverse economic effects. One study found that only after uncoupling joint orders of Vitamin B12 and serum folate tests from predefined order sets, laboratory test cost decreased by about $\$ 26,719$ per year [16]. Similarly, another study removed the option to order daily routine tests from automated admission order sets and found savings of $\$ 26,416$ after 2 months [25].

\section{Cost-effectiveness-analysis models}

In Table 4, we present an overview of studies that conducted a cost-effectiveness-analysis (CEA) of EHR-based CDS interventions and include various cost data as well as economic outcome measures. One such economic outcome measure is the incremental cost-effectiveness ratio (ICER), which depicts the incremental change in costs divided by the incremental change in health outcome or effect.

Cost-effectiveness analyses aim to reveal the trade-offs in resource-allocation decisions [41]. In this context, it is essential to investigate when and to what extend upfront and maintenance costs for an EHR based CDS system will be amortized by its benefits. The benefits can be measured in health outcomes, such as quality adjusted life years (QALYs), or the reduction of unnecessary healthcare utilization.

Generally, two studies report an increase in healthcare expenditure from a societal perspective $[26,33]$ while the other two report cost savings from a societal perspective and the medical group's perspective $[5,35]$. Notably, the measurement of effectiveness was single study-based estimates in all four studies.

Regarding the consideration of upfront implementation cost, Gong et al. [5] include only base case consolidated cost data of $\$ 1.91$ for a cohort of 100.000 individuals based on expert opinions. Sharifi et al. [26] include intervention start-up cost for EHR modification of \$2.7 mill. as well as other direct costs, such as professional care provider training. Michaelidis et al. [33] report implementation and 
Table 3 Application areas and cost outcome measures in relation to CDS intervention categories 1.-7

\begin{tabular}{|c|c|c|c|c|}
\hline \multirow[t]{2}{*}{ Study } & \multirow{2}{*}{\multicolumn{2}{|c|}{ Size $^{\mathrm{a}} \quad$ Application area }} & \multirow[t]{2}{*}{$\begin{array}{l}\text { CDS intervention } \\
\text { period (in month) }\end{array}$} & $\begin{array}{l}\text { Change in cost outcome per year } \\
\text { (in US\$, if not other stated) }\end{array}$ \\
\hline & & & & per activated alert \\
\hline
\end{tabular}

1. Medication (dosing) support

Tamblyn [19] Medium Reduce out-of-pocket cost for patients with uncomplicated hypertension

\section{Order facilitator}

Bolles [17] Small Inappropriate test ordering for specialized HIV laboratory testing

Schnaus [27] Large The order "complete blood count without differential" unintentionally changed to "complete blood count with differential"

\section{Point of care alerts or reminders}

\begin{tabular}{|c|c|c|}
\hline Gong [5] & Medium & $\begin{array}{l}\text { Inappropriate antibiotic prescribing for acute } \\
\text { respiratory infection }\end{array}$ \\
\hline Chen D [13] & Large & $\begin{array}{l}\text { Reduce unnecessary imaging studies in patients } \\
\text { with low back pain }\end{array}$ \\
\hline Chin [15] & Large & Decrease routine testing for $25(\mathrm{OH})$ vitamin $D$ levels \\
\hline Bejjanki [20] & Large & Reduce 17 frequently used duplicate laboratory tests \\
\hline Chen JR [22] & Small & $\begin{array}{l}\text { Directing the physician to order penicillin allergy testing } \\
\text { for patients receiving aztreonam }\end{array}$ \\
\hline Heekin [23] & Large & Adherence to 18 different Choosing Wisely (CW) alerts \\
\hline Sharifi [26] & Small & Clinical childhood obesity intervention \\
\hline Goodnough [36] & Large & Reduce overutilization in blood transfusion procedure \\
\hline Razavi [37] & Small & $\begin{array}{l}\text { Reduce unnecessary waste in transfusion practice and } \\
\text { blood use of cardiothoracic surgeons }\end{array}$ \\
\hline Bridges [38] & mall & Reduce unnecessary acute hepatitis profile laboratory tests \\
\hline
\end{tabular}

4. Relevant information display department utilizers

\section{Expert systems}

$$
\text { Large }
$$

Antimicrobial stewardship that facilitates the post-prescription review process

6. Workflow support

none

\section{Restriction of choice}

MacMillan [21] - Large

Konger [29] Large

Reduce unnecessary frequent red blood cell folate tests

Procop (b) [32] Large

\section{Studies with combined multiple CDS intervention categories}

1. Medication (dosing) support \& 3 . Point of care alerts or reminders

$\begin{array}{lll}\text { Stenner [30] } & \text { Large } & \text { ePrescribing tool for therapeutic interchange prescribing } \\ \text { Forrester [35] } & \text { Medium } & \text { CPOE CDS vs. paper-based prescribing in reducing } \\ & & \text { medication errors and adverse drug events (ADE) }\end{array}$

\section{Order facilitator \& 3. Point of care alerts or reminders}

Goetz [16] Large Decrease serum folate laboratory testing

\section{Order facilitator \& 6 . Workflow support}

Michaelidis [33] Medium Reduce inappropriate antibiotic prescribing for acute bronchitis 
Table 3 Application areas and cost outcome measures in relation to CDS intervention categories 1.-7 (Continued)

\begin{tabular}{|c|c|c|c|c|c|}
\hline \multirow[t]{2}{*}{ Study } & \multirow[t]{2}{*}{ Size $\mathrm{a}^{\mathrm{a}}$} & \multirow[t]{2}{*}{ Application area } & \multirow[t]{2}{*}{$\begin{array}{l}\text { CDS intervention } \\
\text { period (in month) }\end{array}$} & \multicolumn{2}{|c|}{$\begin{array}{l}\text { Change in cost outcome per year } \\
\text { (in US\$, if not other stated) }\end{array}$} \\
\hline & & & & per patient & per activated alert \\
\hline \multicolumn{6}{|c|}{ 2. Order facilitator \& 7. Restriction of choice } \\
\hline Sadowski [25] & Medium & $\begin{array}{l}\text { Reduce admission order sets, which allowed multiple } \\
\text { routine tests to be ordered repetitively }\end{array}$ & 2 & $-\$ 55^{e}$ & \\
\hline \multicolumn{6}{|c|}{ 3. Point of care alerts or reminders \& 7. Restriction of choice } \\
\hline Marcelin [14] & Large & $\begin{array}{l}\text { Reduce inappropriate gastrointestinal pathogen panel } \\
\text { testing }\end{array}$ & 15 & & $n / a^{h}$ \\
\hline Felcher [28] & Medium & Reduce unnecessary Vitamin D testing & 6 & $-\$ 157$ & \\
\hline Procop (a) [31] & Medium & Unnecessary duplicate laboratory testing & 12 & & $\begin{array}{l}\text { Hard-Stop }-\$ 16.08 \\
\text { Smart-Alert }-\$ 3.52\end{array}$ \\
\hline
\end{tabular}

\footnotetext{
a Size is defined as the following:
}

Number of patients or encounters involved

0-999 small size

1000-10,000 medium-size

$>10,000$ large size

If the patient count was not reported, we applied this range of criteria to the number of triggered alerts in total

${ }^{b}$ All cost outcomes were scaled and calculated to the overall change in cost outcome per year and per patient or activated alert. Values (for $>\$ 1$ ) are rounded to full integer numbers. Because of the predominantly short CDS intervention period time range, a discount factor is not used for calculation. The originally reported cost data is mentioned in an additional file (see Additional file 2) [64-68]

' Cost estimation based on a model

d No statistically significant differences between control and intervention group regarding out-of-pocket cost per patient

e Estimated reduced cost per inpatient day per year after intervention 1

${ }^{f}$ No information regarding the number of patients or alerts. Overall cost outcome per year: $-\$ 51,206$

${ }^{9}$ No information regarding the number of patients or alerts. Overall cost outcome per year: - $\$ 157,782$

${ }^{\mathrm{h}}$ No information regarding the number of patients or alerts. Overall cost outcome per year: $-\$ 53,600$

maintenance cost data, which is physician education per hour and medical record and CDS programming per patient of $\$ 18$ in the base case. Lastly, Forrester et al. [35] report CPOE CDS system cost as hardware, software, and maintenance costs starting from $\$ 373,000$ in year one to $\$ 92,000$ after 5 years, as well as personnel, $\$ 555,000$ in year one, and indirect costs as $3 \%$ of the total cost. Interestingly, the indirect costs also include the HITECH Meaningful Use incentives in their model to simulate the financial incentives by the Centers for Medicare \& Medicaid Services in the US [35, 42].

\section{Studies lack consideration of all cost components}

Despite revealing significant potentials for cost-savings, we could not assess the quality of the included studies because of missing cost information or non-consideration of all relevant cost components. According to the Consolidated Health Economic Evaluation Reporting Standards (CHEE RS) statement, most of the reported recommendations were not satisfied [43]. All 23 non-model studies (85\%) only calculate the economic outcome based on financial data reported before and after intervention implementation. For instance, this results from the computation of

Table 4 Overview of cost data and cost outcome of model-based studies $(n=4)$

\begin{tabular}{|c|c|c|c|c|c|}
\hline Study & $\begin{array}{l}\text { Model time } \\
\text { horizon (years) }\end{array}$ & Choice of model & $\begin{array}{l}\text { Implementation and } \\
\text { maintenance costs }\end{array}$ & Total budget impact & ICER \\
\hline Gong et al. [5] & 30 & Markov model & $\begin{array}{l}\$ 1.91 \text { base case for } 100,000 \\
\text { individuals [preexisting EHR] }\end{array}$ & $\begin{array}{l}\text { CDS intervention } \\
\$ 17.32 \text { mill. } \\
\text { Control } \\
\$ 17.82 \text { mill. }\end{array}$ & $\begin{array}{l}\$ 99.8 \text { per QALY in base } \\
\text { case scenario }\end{array}$ \\
\hline Sharifi et al. [26] & 10 & $\begin{array}{l}\text { Monte Carlo } \\
\text { micro-simulation }\end{array}$ & $\begin{array}{l}\$ 23,542 \text { per } \mathrm{PCP} \text { group } \\
\text { [preexisting EHR] }\end{array}$ & $\begin{array}{l}\text { CDS intervention } \\
+\$ 239 \text { mill. }\end{array}$ & $\$ 237$ per BMI unit reduction \\
\hline Michaelidis et al. [33] & 5 & Decision analytic tree & $\begin{array}{l}\$ 18 \text { base case - medical record } \\
\text { programming [preexisting EHR] }\end{array}$ & $\begin{array}{l}\text { CDS intervention } \\
\$ 2802^{a} \\
\text { Control (usual care) } \\
\$ 2768^{a}\end{array}$ & $\begin{array}{l}\$ 51.51 \text { per antibiotic } \\
\text { prescription safely avoided }\end{array}$ \\
\hline Forrester et al. [35] & 5 & Decision analytic tree & $\begin{array}{l}\$ 1,773,000 \\
5 \text { years CPOE system cost }\end{array}$ & $\begin{array}{l}\text { CDS CPOE system } \\
\$ 25 \text { mill. } \\
\text { Control (paper system) } \\
\text { \$43mill. }\end{array}$ & $\$ 110$ per ADE averted ${ }^{b}$ \\
\hline
\end{tabular}

${ }^{a}$ Cumulative 5-year societal cost per five cases of acute bronchitis

${ }^{b}$ Documented only for the explored modelling scenario no. 2: The Everett Clinic achieved no reduction in paper chart pulls throughout the 5-year time horizon, to explore the effect of inefficiency from running a paper and electronic system in parallel 
price per healthcare resource utilization multiplied by the quantity of used healthcare resources or services. Thus, even though it was not intended in those studies, it is necessary to mention that only four of the included studies adhere to sound economic evaluations as recommended by CHEERS [5, 35].

The challenge of heterogeneity for the CEA is also aggravated by considering different cost outcomes. Two studies neither report an incremental cost effectiveness ratio (ICER) for a predefined threshold directly, nor do they include comparative metrics $[33,35]$. Other standardized metrics, such as the return on investment or net present value, were also not examined in the included studies. Only one study reports on the net monetary benefit (NMB) of the intervention in relation to a predefined threshold $[5,44]$.

\section{Additional studies worth mentioning}

Notably, five more studies [45-49] meet most of our inclusion criteria but were excluded due to various, although little, deviations. Three studies [45-47] report cost-savings after a bundle of information technology was implemented simultaneously, but the economic benefit could not solely be attributed to the EHR based CDS intervention. The fourth publication is an NHS health technology assessment (HTA) report [48]. In this HTA, an RCT was conducted in 79 general practices in the UK in which a multi-component intervention was installed using EHRs to reduce the number of antibiotic prescriptions for respiratory infections. The authors perform a basic costanalysis focusing on the number of provider consultations as the cost of healthcare utilization. However, they found no difference in the cost outcome between the intervention and control period.

The last study worth mentioning compared retrospectively generated alerts by an advanced machine learning CDS system to alerts triggered through the home-grown EHR based CDS system [49]. The authors calculated the healthcare cost of potentially prevented adverse drug events and medication errors and found that the advanced machine learning CDS system gave $68.2 \%$ more alerts resulting in cost savings of $\$ 60.67$ per alert. After extrapolating these results to a local patient population of 747,985, they estimated savings of $\$ 1,294,457$ over 5 years [49].

\section{Discussion}

Evaluating the economic impact of EHR-based CDS interventions and their potential to increase value in healthcare remains a significant challenge. Even though we found that 22 studies report cost savings, most of them do not include developing or maintaining costs. Therefore, we could not draw a sound correlation between vendor-purchased or home-grown systems' costs to their economic benefit. Nonetheless, this study reveals several use cases with coherent CDS tools that have proven to be cost-saving and could be eligible for other healthcare providers, clinic managers, and researchers for implementation or further exploration.

With the majority of implemented CDS interventions based on point-of-care alerts, the question remains on how more algorithm-based expert systems and multiple interventions will have synergy effects on the economic impact. Considering the amount of alerts and the healthcare provider's time expense, a process-cost analysis, such as the time-driven activity based costing approach, could be combined with the CEA to achieve a better understanding of the whole cost cycle as well as productivity effects for healthcare entities [50,51]. Generally, cost outcome measures continue to require comparative metrics, for instance, as used by Mathias et al., the cost per useful alert [52]. In a simple model, the authors introduce this measure to analyze how different parameters affect the cost of implementing EHR based CDS alerts for genomic precision medicine [52]. However, for future economic evaluations of EHR based CDS interventions, a more specific approach for individual application areas or focus on medical risk factors is needed to draw meaningful conclusions from cost and outcome comparisons [9]. Moreover, decision-analytic modelling techniques, e.g., Markov models, enable the evaluation of multiple income and outcome parameters. They address downstream costs or savings that may result from the introduction of health information technology. These complex modelling approaches are necessary in order to consider various health outcomes resulting from EHR CDS systems, e.g., prevention of adverse events [5].

Another economic challenge to consider is CPOE systems with default lists or opt-out options of orderable tests as well as predefined order sets. The automation of orders through such order sets or joint-order options could ultimately lead to an increase in costs and a decrease of value $[53,54]$. For example, the rate of unnecessary laboratory tests can increase when healthcare professionals tend to accept the whole order set rather than de-selecting single order items [17]. This can be explained by alert fatigue, which must not directly be related to the order set, in combination with the 'button clicking syndrome', which explains the inducement of moving along inattentively $[17,54]$. Apart from the direct economic factors, other potential benefits of order sets and joint-order options, such as improved adherence to clinical guidelines or patient safety outcomes, are not sufficiently addressed by the included studies. This again highlights the importance of further profound health economic evaluations.

Finally, one study also reported an increase in costs after an unplanned change in the CDS system [27]. Such malfunctions or unintended errors, when caused by 
newly integrated health information technology, are referred to as 'e-Iatrogenesis' [55]. These may also lead to yet another cost-driver and possibly cause unpredictable economic damage $[56,57]$.

\section{Transferability for other countries}

All included studies where based on cost data and trials from the United States or Canada. Consequently, current research progress on the economic potentials of EHR based CDS systems on rising healthcare expenditure in Europe and worldwide cannot be derived. We found recent studies that evaluate the cost-effectiveness of a stand-alone CPOE CDS system in the Netherlands [58], or compare the effectiveness of an EHR based CDS intervention in the US, UK, Republic of Korea, and Belgium [59]. Another RCT explored the effectiveness of an EHR based CDS intervention for patients with atrial fibrillation and a high risk of stroke in Sweden [60]. Nevertheless, we found no study that has evaluated the potential for increasing value in this present highly promising field of health information technology outside of North America.

However, this study reveals promising cost savings for already implemented health information technology. Even though implementation cost was not considered, on a long-term view, these results reveal the potential for cost-savings once implementation cost is amortized. Therefore, the sooner large health information technology systems will be implemented in other countries around the world and evaluated economically, the earlier cost-benefits and return on investments can be realized.

\section{Support from policymakers could accelerate economic benefits}

Interestingly, Forrester et al. [35] include monetary incentives provided by the Meaningful Use Initiative in the US in their CEA. This financial support covered only a small percentage of total implementation cost in their developed model as incentive-eligible prescribers received $\$ 42,000$ over 5 years. Nevertheless, this contributed to the investigated cost-effectiveness of an EHR based CDS intervention compared to paper-based prescriptions. Therefore, how policymakers worldwide intend to support EHR adoption and incentivize embedded CDS systems financially is a critical factor for the economic success of such systems. High upfront implementation cost constitute a significant burden for healthcare entities, especially for smaller to middle-sized practices and hospitals [61]. For instance, a systematic review of EHR embedded CDS systems for cardiovascular disease prevention derived the mean annual cost of development, implementation, and ongoing costs of operations to be $\$ 102$ per patient and $\$ 6056$ per practice for small practices, and $\$ 49$ per patient and $\$ 35,201$ per practice for medium-sized practices [9].
Finally, achieving a decrease in healthcare expenditure should never influence a patient's quality of life or disease treatment in a negative way. Even though eliminating a laboratory order option from a CPOE system led to cost-savings, each patient's value and health outcome is of the highest importance and should be individually assessed. Future economic evaluations of EHR based CDS systems should focus more on the potentials of health benefits that could be achieved, such as through reduced antibiotic prescriptions or reduced adverse drug events, rather than proving to have effectively reduced laboratory test cost. In the end, competing on shifting costs will not change anything about the primary goal of decision stewardship, and that is to increase value in healthcare [62].

\section{Limitations}

There are some limitations to this study. Firstly, we only considered English language literature and, therefore, might not have included international publications in other languages that indeed report on the information technology progress made by other countries regarding the linkage of CDS systems to an existing EHR. Another limitation is the exclusion of EHR cost and price display interventions. This decision was based on another recent systematic review, which found that cost display interventions in EHR CPOE systems do not affect the efficiency and effectiveness domain of healthcare quality [63]. We also excluded other non-monetary impact measures, such as length of stay, which necessarily also refers to the economic impact of EHR based CDS implementations.

Overall, our findings might be biased since we included all types of studies as well as all kinds of monetary outcomes. Due to the lack of economic evaluations, included studies tend to declare high cost-savings but only consider little to no cost components regarding the implementation and maintenance of such a complex information system. In addition, authors might have been tempted to calculate cost-savings only when the implemented intervention proved effective. Finally, we found that some studies not necessarily mention the calculated economic outcome in the title or abstract of their publication. Therefore, we might have excluded studies that did not initially meet our inclusion criteria by following the PRISMA guidelines.

\section{Conclusion}

Clinical decision support interventions based on electronic health records have an overall positive economic impact. Predominantly point-of-care alerts concerning unnecessary laboratory testing, efficient transfusion practice, or reduction of antibiotic prescription emerged as application areas with already promising potential for high-cost savings. Nonetheless, most studies lack 
consideration of coherent cost components as well as comparative metrics. Therefore, the economic dimension of EHR based CDS interventions needs to be further explored. High-quality cost-effectiveness or costutility analyses, which include more extensive cost data and consider different economic perspectives, are needed to draw a sound conclusion. Finally, introducing personalized health services based on peoples' electronic health records is yet another promising research field with high potential for further increasing value in healthcare and should receive more attention in future research.

\section{Supplementary information}

Supplementary information accompanies this paper at https://doi.org/10. 1186/s12913-020-05688-3.

Additional file 1. Search strategy and developed search terms for different databases.

Additional file 2. Evidence synthesis and summary of included studies $(n=27)$.

\section{Abbreviations \\ ADE: Adverse drug events; BPA: Best-practice-alerts; CDS: Clinical decision support; CEA: Cost-effectiveness-analysis; CHEERS: Consolidated Health Economic Evaluation Reporting Standards; CPOE: Computerized provider order entry; CW: Choosing Wisely; EHR: Electronic health record; HTA: Health technology assessment; ICER: Incremental cost-effectiveness ratio; NMB: Net monetary benefit; QALY: Quality adjusted life years; RCT: Randomized controlled trial; PRISMA: Preferred Reporting Items for Systematic Reviews and Meta Analyses}

\section{Acknowledgements}

Not applicable.

\section{Authors' contributions}

$\mathrm{DL}$ conceptualized the study. DL and AW conducted the literature searches, literature screening, as well as the analyses. DL drafted the manuscript, and $\mathrm{DL}, \mathrm{AW}$, and EB contributed to refining all sections and critically editing the paper. The author(s) read and approved the final manuscript.

\section{Funding}

This work has received funding from the European Union's Horizon 2020 research and innovation program under the grant agreement No. 826117 Smart4Health - Building a citizen-centered EU-EHR exchange for personalized health. The funding body had no role in the design of the study, collection or data analysis. Open Access funding provided by Projekt DEAL.

\section{Availability of data and materials}

Not applicable.

\section{Ethics approval and consent to participate}

Not applicable.

\section{Consent for publication}

Not applicable.

\section{Competing interests}

The authors declare that they have no competing interests.

\section{Author details}

${ }^{1}$ Digital Health Center, Hasso Plattner Institute, University of Potsdam, Prof.-Dr.-Helmert-Str. 2-3, 14482 Potsdam, Germany. ${ }^{2}$ Hasso Plattner Institute for Digital Health at Mount Sinai, Icahn School of Medicine at Mount Sinai, New York, NY 10029, USA.
Received: 15 May 2020 Accepted: 25 August 2020

Published online: 15 September 2020

\section{References}

1. OECD. Health at a glance 2017: OECD indicators. Paris: OECD Publishing; 2017. https://doi.org/10.1787/health_glance-2017-en. Accessed 1 Oct 2019

2. OECD (2019). OECD Health Statistics 2019. https://www.oecd.org/health/ health-data.htm. Accessed 1 Dec 2019.

3. Shrank WH, Rogstad TL, Parekh N. Waste in the US health care system: estimated costs and potential for savings. JAMA. 2019;322(15):1501-9 https://doi.org/10.1001/jama.2019.13978.

4. McGinn T. Putting meaning into meaningful use: a roadmap to successful integration of evidence at the point of care. JMIR Med Inform. 2016;4(2):e16 https://doi.org/10.2196/medinform.4553.

5. Gong $\mathrm{CL}$, Zangwill KM, Hay JW, et al. Behavioral economics interventions to improve outpatient antibiotic prescribing for acute respiratory infections: a costeffectiveness analysis. J Gen Intern Med. 2019;34(6):846-54 https://doi. org/10.1007/s11606-018-4467-x

6. Atkins D. So many nudges, so little time: can cost-effectiveness tell us when it is worthwhile to try to change provider behavior? J Gen Intern Med. 2019; 34(6):783-4 https://doi.org/10.1007/s11606-019-04871-5.

7. Cho I, Bates DW. Behavioral economics interventions in clinical decision support systems. Yearb Med Inform. 2018;27(1):114-21 https://doi.org/10. 1055/s-0038-1641221.

8. Moher D, Liberati A, Tetzlaff J, Altman DG, PRIS MA Group. Preferred reporting items for systematic reviews and meta-analyses: the PRIS MA statement. PLoS Med. 2009;6(7):e1000097 https://doi.org/10.1371/journal. pmed.1000097.

9. Jacob V, Thota AB, Chattopadhyay SK, et al. Cost and economic benefit of clinical decision support systems for cardiovascular disease prevention: a community guide systematic review. J Am Med Inform Assoc. 2017;24(3): 669-76 https://doi.org/10.1093/jamia/ocw160.

10. Moja L, Kwag KH, Lytras T, et al. Effectiveness of computerized decision support systems linked to electronic health records: a systematic review and metaanalysis. Am J Public Health. 2014;104(12):e12-22 https://doi.org/10. 2105/AJPH.2014.302164.

11. Bright TJ, Wong A, Dhurjati $R$, et al. Effect of clinical decision-support systems: a systematic review. Ann Intern Med. 2012;157(1):29-43 https://doi. org/10.7326/0003-4819-157-1-201207030-00450.

12. Wright A, Sittig DF, Ash JS, et al. Development and evaluation of a comprehensive clinical decision support taxonomy: comparison of frontend tools in commercial and internally developed electronic health record systems. J Am Med Inform Assoc. 2011;18(3):232-42 https://doi.org/10.1136/ amiajnl-2011-000113.

13. Chen D, Bhambhvani HP, Hom J, et al. Effect of electronic clinical decision support on Imaging for the evaluation of acute low back pain in the ambulatory care setting. World Neurosurg. 2019;\$1878-8750(19):32867 https://doi.org/10.1016/j.wneu.2019.11.03.

14. Marcelin J, Brewer C, Beachy M, et al. Hardwiring diagnostic stewardship using electronic ordering restrictions for gastrointestinal pathogen testing Infect Control Hosp Epidemiol. 2019;40(6):668-73 https://doi.org/10.1017/ ice.2019.78.

15. Chin KK, Hom J, Tan M, et al. Effect of electronic clinical decision support on 25(OH) vitamin D testing. J Gen Intern Med. 2019:34(9):1697-9 https://doi. org/10.1007/s11606-019-05057-9.

16. Goetz C, Di Capua J, Lee I, et al. A student-led, multifaceted intervention to decrease unnecessary Folate ordering in the inpatient setting. J Healthc Qual. 2019;41(5):e54-60 https://doi.org/10.1097/JHQ.0000000000000177.

17. Bolles K, Woc-Colburn L, Hamill RJ, et al. Ordering patterns and costs of specialized laboratory testing by hospitalists and house staff in hospitalized patients with HIV at a county hospital: An opportunity for diagnostic stewardship. Open Forum Infect Dis. 2019;6(6):ofz158 https://doi.org/10. 1093/ofid/ofz158.

18. Fertel BS, Podolsky SR, Mark J, et al. Impact of an individual plan of care for frequent and high utilizers in a large healthcare system. Am J Emerg Med. 2019;37(11):2039-42 https://doi.org/10.1016/j.ajem.2019.02.032.

19. Tamblyn R, Winslade N, Qian CJ, et al. What is in your wallet? A cluster randomized trial of the effects of showing comparative patient out-ofpocket costs on primary care prescribing for uncomplicated hypertension. Implement Sci. 2018;13(1):7 https://doi.org/10.1186/s13012-017-0701-x. 
20. Bejjanki H, Mramba LK, Beal SG, et al. The role of a best practice alert in the electronic medical record in reducing repetitive lab tests. Clinicoecon Outcomes Res. 2018;10:611-8 https://doi.org/10.2147/CEOR.S167499.

21. MacMillan TE, Gudgeon P, Yip PM, et al. Reduction in unnecessary red blood cell folate testing by restricting computerized physician order entry in the electronic health record. Am J Med. 2018;131(8):939-44 https://doi. org/10.1016/j.amjmed.2018.03.044.

22. Chen JR, Tarver SA, Alvarez KS, et al. Improving aztreonam stewardship and cost through a penicillin allergy testing clinical guideline. Open Forum Infect Dis. 2018;5(6):ofy106 https://doi.org/10.1093/ofid/ofy106.

23. Heekin AM, Kontor J, Sax HC, et al. Choosing wisely clinical decision support adherence and associated inpatient outcomes. Am J Manag Care. 2018; 24(8):361-6.

24. Nault V, Pepin J, Beaudoin M, et al. Sustained impact of a computer-assisted antimicrobial stewardship intervention on antimicrobial use and length of stay. J Antimicrob Chemother. 2017;72(3):933-40 https://doi.org/10.1093/jac/ dkw468.

25. Sadowski BW, Lane AB, Wood SM, et al. High-value, cost-conscious care: Iterative systems-based interventions to reduce unnecessary laboratory testing. Am J Med. 2017;130(9):1112.e1-7 https://doi.org/10.1016/j.amjmed. 2017.02.029.

26. Sharifi M, Franz C, Horan CM, et al. Cost-effectiveness of a clinical childhood obesity intervention. Pediatrics. 2017;140(5):e20162998 https://doi.org/10. 1542/peds.2016-2998.

27. Schnaus MJ, Michalik M, Skarda P. Effects of electronic medical record display on provider ordering behavior: leveraging the EMR to improve quality and costs. Am J Med. 2017;130(12):1366-71 https://doi.org/10.1016/j. amjmed.2017.08.019.

28. Felcher AH, Gold R, Mosen DM, et al. Decrease in unnecessary vitamin D testing using clinical decision support tools: making it harder to do the wrong thing. J Am Med Inform Assoc. 2017;24(4):776-80 https://doi.org/10. 1093/jamia/ocw182.

29. Konger RL, Ndekwe P, Jones $G$, et al. Reduction in unnecessary clinical laboratory testing through utilization management at a US government veterans affairs hospital. Am J Clin Pathol. 2016;145(3):355-64 https://doi. org/10.1093/ajcp/aqv092.

30. Stenner SP, Chakravarthy $\mathrm{R}$, Johnson KB, et al. ePrescribing: reducing costs through in-class therapeutic interchange. Appl Clin Inform. 2016; 7(4):1168-81.

31. Procop GW, Keating C, Stagno P, et al. (a). Reducing duplicate testing: a comparison of two clinical decision support tools. Am J Clin Pathol. 2015; 143(5):623-6 https://doi.org/10.1309/AJCPJOJ3HKEBD3TU.

32. Procop GW, Yerian LM, Wyllie R, et al. (b). Duplicate laboratory test reduction using a clinical decision support tool. Am J Clin Pathol. 2014; 141(5):718-23 https://doi.org/10.1309/AJCPOWHOIZBZ3FRW.

33. Michaelidis $\mathrm{Cl}$, Kern MS, Smith KJ. Cost-effectiveness of decision support strategies in acute bronchitis. J Gen Intern Med. 2015;30(10):1505-10 https://doi.org/10.1007/s11606-015-3289-3.

34. Shaha SH, Gilbert-Bradley D. Improved immediate and continued-care outcomes for stroke through community-wide data. Stud Health Technol Inform. 2015;209:140-6.

35. Forrester SH, Hepp Z, Roth JA, et al. Cost-effectiveness of a computerized provider order entry system in improving medication safety ambulatory care. Value Health. 2014;17(4):340-9 https://doi.org/10. 1016/j.jval.2014.01.009

36. Goodnough LT, Maggio P, Hadhazy E, et al. Restrictive blood transfusion practices are associated with improved patient outcomes. Transfusion. 2014; 54:2753-9 https://doi.org/10.1111/trf.12723.

37. Razavi SA, Carter AB, Puskas JD, et al. Reduced red blood cell transfusion in cardiothoracic surgery after implementation of a novel clinical decision support tool. J Am Coll Surg. 2014;219(5):1028-36 https://doi.org/10.1016/j. jamcollsurg.2014.06.012.

38. Bridges SA, Papa L, Norris AE, et al. Duplicated laboratory tests: evaluation of a computerized alert intervention abstract. J Healthc Qual. 2014;36(3):46-53 https://doi.org/10.1111/j.1945-1474.2012.00219.x.

39. Ubel PA, Rosenthal MB. Beyond nudges - when improving health calls for greater assertiveness. N Engl J Med. 2019;380(4):309-11 https://doi.org/10. 1056/NEJMp1806371.

40. Powers EM, Shiffman RN, Melnick ER, et al. Efficacy and unintended consequences of hard-stop alerts in electronic health record systems: a systematic review. J Am Med Inform Assoc. 2018;25(11):1556-66.
41. Neumann PJ, Sanders GD. Cost-effectiveness analysis 2.0. N Engl J Med. 2017;376(3):203-5 https://doi.org/10.1056/NEJMp1612619.

42. Centers for Medicare \& Medicaid Services. Medicare and Medicaid programs; Regulations \& Guidance; Promoting Interoperability Programs. 2020. http://www.cms.gov/Regulations-and-Guidance/Legislation/ EHRIncentivePrograms/index.html . Accessed 26 June 2020.

43. Husereau D, Drummond M, Petrou S, et al. Consolidated health economic evaluation reporting standards (CHEE RS) — explanation and elaboration: a report of the ISPOR health economic evaluations publication guidelines good reporting practices task force. Value Health. 2013;16(2):231-50.

44. Stinnett AA, Mullahy J. Net health benefits: a new framework for the analysis of uncertainty in cost-effectiveness analysis. Med Decis Mak. 1998; 18:S68-80.

45. Graven M, Allen P, Smith I, et al. Decline in mortality with the Belize integrated patient-Centred country wide health information system (BHIS) with embedded program management. Int J Med Inform. 2013;82(10):95463 https://doi.org/10.1016/j.jimedinf.2013.06.003.

46. Riahi S, Fischler I, Stuckey Ml, et al. The value of electronic medical record implementation in mental health care: a case study. JMIR Med Inform. 2017; 5(1):e1.

47. Olchanski N, Dziadzko MA, Tiong IC, et al. Can a novel ICU data display positively affect patient outcomes and save lives? J Med Syst. 2017;41(11): 171 https://doi.org/10.1007/s10916-017-0810-8.

48. Gulliford MC, Juszczyk D, Prevost AT, et al. Electronically delivered interventions to reduce antibiotic prescribing for respiratory infections in primary care: cluster RCT using electronic health records and cohort study. Health Technol Assess. 2019;23(11):1-70 https://doi.org/10.3310/hta23110.

49. Rozenblum R, Rodriguez-Monguio R, Volk LA, et al. Using a machine learning system to identify and prevent medication prescribing errors: a clinical and cost analysis evaluation. Jt Comm J Qual Patient Saf. 2020;46(1): 3-10 https://doi.org/10.1016/j.jcjq.2019.09.008.

50. Keel G, Savage C, Rafiq M, et al. Time-driven activity-based costing in health care: a systematic review of the literature. Health Policy. 2017;121(7):755-63 https://doi.org/10.1016/j.healthpol.2017.04.013.

51. Campanale C, Cinquini $L$, Tenucci A. Time-driven activity-based costing to improve transparency and decision making in healthcare. Management. 2014;11:165-86.

52. Mathias PC, Tarczy-Hornoch P, Shirts BH. Modeling the costs of clinical decision support for genomic precision medicine. AMIA Jt Summits Transl Sci Proc. 2016:2016:60-4 eCollection 2016.

53. Hussain MI, Reynolds TL, Zheng K, et al. Medication safety alert fatigue may be reduced via interaction design and clinical role tailoring: a systematic review. J Am Med Inform Assoc. 2019;26(10):1141-9 https://doi.org/10.1093/ jamia/ocz095.

54. Hakim I, Hathi S, Nair A, et al. Electronic health records and the frequency of diagnostic test orders. Am J Manag Care. 2017;23(1):e16-23.

55. Payne TH, Bates DW, Berner ES, et al. Healthcare information technology and economics. J Am Med Inform Assoc. 2013;20(2):212-7.

56. Wright A, Ai A, Ash J, et al. Clinical decision support alert malfunctions: analysis and empirically derived taxonomy. J Am Med Inform Assoc. 2018; 25(5):496-506 https://doi.org/10.1093/jamia/ocx106.

57. Aaron S, McEvoy DS, Ray S, et al. Cranky comments: detecting clinical decision support malfunctions through free-text override reasons. J Am Med Inform Assoc. 2019;26(1):37-43 https://doi.org/10.1093/jamia/ocy139.

58. Vermeulen KM, van Doormaal JE, Zaal RJ, et al. Cost-effectiveness of an electronic medication ordering system (CPOE/CDSS) in hospitalized patients. Int J Med Inform. 2014;83(8):572-80 https://doi.org/10.1016/j.jimedinf.2014. 05.003 .

59. Cornu P, Phansalkar S, Seger DL, et al. High-priority and low-priority drugdrug interactions in different international electronic health record systems: a comparative study. Int J Med Inform. 2018;111:165-71 https://doi.org/10. 1016/j.jijmedinf.2017.12.027

60. Karlsson LO, Nilsson S, Bång M, et al. A clinical decision support tool for improving adherence to guidelines on anticoagulant therapy in patients with atrial fibrillation at risk of stroke: a cluster-randomized trial in a Swedish primary care setting (the CDS-AF study). PLoS Med. 2018;15(3):e1002528 https://doi.org/10.1371/journal.pmed.1002528.

61. Slight SP, Quinn C, Avery AJ, et al. A qualitative study identifying the cost categories associated with electronic health record implementation in the UK. J Am Med Inform Assoc. 2014;21(e2):e226-31 https://doi.org/10.1136/ amiajnl-2013-002404. 
62. Porter ME. What is value in health care? N Engl J Med. 2010;363(26):2477-81 https://doi.org/10.1056/NEJMp1011024.

63. Mummadi SR, Mishra R. Effectiveness of provider price display in computerized physician order entry (CPOE) on healthcare quality: a systematic review. J Am Med Inform Assoc. 2018;25(9):1228-39 https://doi. org/10.1093/jamia/ocy076.

64. Meeker D, Linder JA, Fox CR, et al. Effect of behavioral interventions on inappropriate antibiotic prescribing among primary care practices: a randomized clinical trial. JAMA. 2016;315(6):562-70 https://doi.org/10.1001/ jama.2016.0275.

65. Taveras EM, Marshall R, Kleinman KP, et al. Comparative effectiveness of childhood obesity interventions in pediatric primary care: a clusterrandomized clinical trial. JAMA Pediatr. 2015;169(6):535-42 https://doi.org/ 10.1001/jamapediatrics.2015.0182.

66. Gonzales R, Anderer T, McCulloch CE, et al. A cluster randomized trial of decision support strategies for reducing antibiotic use in acute bronchitis. JAMA Intern Med. 2013;173(4):267-73 https://doi.org/10.1001/ jamainternmed.2013.1589.

67. Black JT. Capsule Commentary on Michaelidis et al., Cost-Effectiveness of decision support strategies in acute bronchitis. J Gen Intern Med. 2016;31(3): 328 https://doi.org/10.1007/s1 1606-015-3431-2.

68. Devine EB, Hansen RN, Wilson-Norton JL, et al. The impact of computerized provider order entry on medication errors in a multispecialty group practice. J Am Med Inform Assoc. 2010;17(1):78-84 https://doi.org/10.1197/ jamia.M3285.

\section{Publisher's Note}

Springer Nature remains neutral with regard to jurisdictional claims in published maps and institutional affiliations.

Ready to submit your research? Choose BMC and benefit from:

- fast, convenient online submission

- thorough peer review by experienced researchers in your field

- rapid publication on acceptance

- support for research data, including large and complex data types

- gold Open Access which fosters wider collaboration and increased citations

- maximum visibility for your research: over $100 \mathrm{M}$ website views per year

At $\mathrm{BMC}$, research is always in progress.

Learn more biomedcentral.com/submissions 